\title{
Atividade antimicrobiana de óleos essenciais no controle de alguns fitopatógenos fúngicos in vitro e no tratamento de sementes
}

\author{
HILLEN, T. ${ }^{1}$; SCHWAN-ESTRADA, K.R.F. ${ }^{1 *}$; MESQUINI, R.M. ${ }^{1}$; CRUZ, M.E.S. ${ }^{1}$; STANGARLIN, J.R. ${ }^{2}$; \\ NOZAKI, M. ${ }^{1}$ \\ ${ }^{1}$ Universidade Estadual de Maringá (UEM/PR), Departamento de Agronomia, Avenida Colombo, 5790, CEP: 87.020- \\ 200, Maringá-Brasil ${ }^{2}$ Universidade Estadual do Oeste do Paraná (UNIOESTE/PR), Rua Pernambuco 1777, CEP: \\ 85960-000, Marechal Cândido Rondon-Brasil *schwan@wnet.com.br
}

\begin{abstract}
RESUMO: Este trabalho verificou o efeito dos óleos essenciais (OE) extraídos de Eremanthus erythropappus (candeia), Cymbopogon martinii (palmarosa) e de Rosmarinus officinalis (alecrim) no crescimento micelial de alguns fitopatógenos fúngicos e no tratamento de sementes de milho, soja e feijão. No teste in vitro, alíquotas de 20,40,60, 100, 200, 500 e $1000 \mu \mathrm{L}$ de cada um dos óleos essenciais foram distribuídas na superfície do meio de cultura. Posteriormente, discos de meio de cultura com micélio de Alternaria carthami, Alternaria sp. e Rhizoctonia solani foram transferidos para o centro de cada placa. $O$ crescimento foi mensurado e calculada a taxa de inibição do crescimento micelial (ICM). Para verificar o efeito dos OE na germinação das sementes utilizou-se a aplicação deles por fumigação. Foi avaliada a percentagem de sementes germinadas e a incidência de patógenos nas sementes. Sobre o crescimento micelial, o óleo de palmarosa inibiu completamente todos os patógenos fúngicos, independentemente da concentração. Já os óleos de candeia e alecrim foram melhores quando foram adicionadas alíquotas superiores a 200 $\mu \mathrm{L}$. Os óleos influenciaram diferentemente a germinação e a sanidade das sementes de milho, soja e feijão.
\end{abstract}

Palavras-chave: controle alternativo, doenças de plantas, crescimento micelial

\begin{abstract}
Antimicrobial activity of essential oils on the in vitro control of some fungal phytopathogens and on seed treatment. This study aimed to verify the effect of essential oils (EO) extracted from Eremanthus erythropappus ("candeia") Cymbopogon martinii ("palmarosa") and Rosmarinus officinalis (rosemary) on the mycelial growth of some fungal phytopathogens, as well as on the treatment of corn, soybean and bean seeds. In the in vitro test, aliquots of 20, 40, $60,100,200,500$ and $1000 \mu \mathrm{L}$ of each essential oil were distributed on the surface of the culture medium. Then, discs of culture medium with mycelium of Alternaria carthami, Alternaria sp and Rhizoctonia solani were transferred to the center of each plate. Growth was measured and the mycelial growth inhibition rate (MGI) was calculated. To verify the effect of EO on seed germination, application of oils was by means of fumigation. Percentage of germinated seeds and their incidence of pathogens were evaluated. For mycelial growth, "palmarosa" oil completely inhibited all fungal pathogens, regardless of the concentration. On the other hand, "candeia" and rosemary oils were better when aliquots higher than $200 \mu \mathrm{L}$ were added. The oils differently influenced the germination and health of corn, soybean and bean seeds.
\end{abstract}

Key words: alternative control, plant diseases, micelial growth

\section{INTRODUÇÃO}

Alguns dos problemas associados à utilização de produtos químicos para o controle de doenças em plantas incluem frequentes falhas no controle devido à aquisição de resistência por parte dos fitopatógenos, contaminação ambiental, entre outros. Em função destas preocupações houve incentivo para que pesquisadores e produtores buscassem novos caminhos para o controle de doenças nas mais diferentes culturas (Venzon et al., 2006). Neste contexto, subprodutos como óleos essenciais, extratos brutos e tinturas, oriundos de plantas medicinais têm sido estudados uma vez que

Recebido para publicação em 30/06/2009

Aceito para publicação em 12/03/2012

Rev. Bras. PI. Med., Botucatu, v.14, n.3, p.439-445, 2012. 
apresentam na composição substâncias com propriedades fungicidas e/ou fungitóxicas (Matos, 1997). Além de serem caracterizados como metabólitos secundários de plantas e de baixa toxicidade a humanos, são amplamente testados no controle in vitro e in vivo de fitopatógenos e no tratamento de sementes (Médice et al., 2007; Pereira et al., 2008; Rodrigues et al., 2006; Silva \& Bastos, 2007). A exploração da bioatividade antimicrobiana utilizando estes compostos secundários constitui-se em mais uma forma potencial para o controle de doenças em plantas cultivadas (Schwan-Estrada \& Stangarlin, 2005). Sendo assim, este trabalho avaliou a atividade antimicrobiana de óleos extraídos de Eremanthus erythropappus (candeia), Cymbopogon martinii (palmarosa) e de Rosmarinus officinalis (alecrim) na inibição do crescimento micelial de Alternaria carthami, Alternaria sp. e de Rhizoctonia solani, bem como, a eficiência desses óleos na manutenção da qualidade fisiológica e sanitária de sementes de soja, feijão e milho.

\section{MATERIAL E MÉTODO}

\section{Obtenção dos fungos fitopatogênicos}

Os isolados fúngicos de Alternaria carthami, Alternaria sp. e Rhizoctonia solani foram obtidos da coleção de fungos do laboratório de Fitopatologia da Universidade Estadual de Maringá, PR. Estes foram cultivados em BDA (batata-dextrose-ágar) e mantidos a $25^{\circ} \mathrm{C} \pm 2^{\circ} \mathrm{C}$ e fotoperíodo de $12 \mathrm{~h}$ de luz e utilizados com 10 dias de crescimento em BDA.

\section{Obtenção e extração dos óleos essenciais}

As plantas medicinais Cymbopogon martinii (Roxb) J.F.Watson (Família Poaceae) e Rosmarinus officinalis L. (Família Lamiaceae) foram coletadas no horto de plantas medicinais e área de cultivo experimental da Universidade Estadual de Maringá. O óleo essencial de C. martinii e de $R$. officinalis foi obtido pelo método de arraste a vapor (Costa, 2005) utilizando folhas frescas e ramos de plantas com $2 \mathrm{e}$ 3 anos de idade, respectivamente, coletadas entre os meses de novembro e dezembro no período da manhã. O óleo essencial de Eremanthus erythropappus (DC) McLeisch (Familia Asteraceae), foi obtido de cavacos do tronco de plantas com 7 anos de idade, cedidas pela Universidade Federal de Lavras. O óleo essencial desta planta foi extraído como descrito anteriormente.

Efeito dos óleos essenciais na inibição do crescimento micelial in vitro de fungos fitopatogênicos

Após a esterilização em filtro milipore (poros com 0,2 mm de diâmetro), alíquotas de 20, 40, 60, $100,200,500$ e $1000 \mu \mathrm{L}$ dos óleos essenciais de alecrim, candeia e palmarosa foram colocadas no centro de placas de Petri contendo cerca de $20 \mathrm{~mL}$ de BDA e distribuídas sobre a superfície do meio com auxílio de alça de Drigalsky. Foi adicionado 1\% (v/v) de Tween 20 para facilitar a emulsificação de cada um dos óleos essenciais. Após 2 horas, discos de 8 $\mathrm{mm}$ de diâmetro contendo micélio dos fungos Alternaria carthami, Alternaria sp. e R. solani com 10 dias de idade, foram depositados no centro das placas, que foram vedadas com filme plástico e o conjunto todo mantido a $28^{\circ} \mathrm{C} \pm 2^{\circ} \mathrm{C}$, no escuro. No tratamento testemunha adicionou-se água destilada e esterilizada ao meio. O delineamento experimental foi inteiramente casualizado, com parcela experimental constituída por quatro placas de petri. O experimento contou com quatro repetições.

As avaliações foram realizadas por meio de medições do diâmetro das colônias desenvolvidas em meio BDA (média de duas medidas diametralmente opostas) iniciadas 24 horas após a instalação do experimento e efetuadas diariamente até que as colônias no tratamento controle cobriram $2 / 3$ da superfície do meio de cultura. Para o cálculo da taxa de inibição do crescimento micelial, utilizou-se a fórmula:

$$
\mathrm{ICM}=\frac{(\text { crescimento na testemunha }- \text { crescimento no óleo essencial } \mathrm{Y})}{\text { crescimento na testemunha }} \cdot 100
$$

Posteriormente, os dados foram submetidos à análise de variância e as médias foram agrupadas pelo teste de Scott-Knott a 5\% de probabilidade.

\footnotetext{
Avaliação do efeito do tratamento de sementes com os óleos essenciais por fumigação na fisiologia e sanidade de sementes

Foram utilizadas sementes de feijão cv carioca, soja cv CD 215 e de milho cv CD 321. As sementes foram previamente desinfetadas com hipoclorito de sódio $5 \%$ e distribuídas formando
}

camada única em caixas tipo Gerbox forradas com camada dupla de papel de filtro, umedecidos com água destilada e esterilizada. As porções de sementes foram fumigadas nestes Gerbox colocando-se, em seu interior um pequeno recipiente contendo $200 \mu \mathrm{L}$ de óleo essencial puro permanecendo desta forma por 10 minutos. No tratamento testemunha utilizouse água e também hipoclorito de sódio (3:1; v:v) como tratamento controle. Neste caso, a parcela foi de 100 sementes para cada tratamento, e 4 repetições por tratamento. Concluída a fumigação, as sementes 
foram retiradas e incubadas em germinador. Decorridos 7 dias, avaliou-se a sanidade das sementes por meio do "blotter test" (Machado, 2000). $O$ delineamento experimental foi inteiramente casualizado com quatro repetições. A parcela experimental constituiu-se em oito caixas Gerbox contendo vinte e cinco sementes/caixa. Os dados foram submetidos à análise de variância e as médias agrupadas pelo teste de Scott-Knott a $5 \%$ de probabilidade, usando o programa Sisvar v.4.6 (Ferreira, 2003).

\section{RESULTADO E DISCUSSÃO}

Os óleos essenciais utilizados em diferentes alíquotas inibiram distintamente o crescimento micelial de A. carthami, Alternaria sp. e R.solani.

O óleo essencial de candeia proporcionou $100 \%$ de inibição do crescimento micelial de todos os fitopatógenos a partir da concentração de $200 \mu \mathrm{L}$ (Figura 1). Esse óleo inibiu totalmente o crescimento micelial de $R$. solani, independentemente da concentração utilizada. Já para Alternaria sp. a inibição total somente ocorreu a partir da alíquota de $60 \mu \mathrm{L}$ e para A. carthami a partir de $100 \mu \mathrm{L}$.

Salustiano et al. (2006) verificaram o efeito do óleo essencial de candeia na inibição in vitro de quatro espécies de ferrugem e sob o crescimento micelial de Cilindrocladium scoparium. Neste caso, o óleo essencial na concentração de $1 \%$ reduziu o crescimento micelial em $25 \%$ e a esporulação em $34 \%$, ambos em relação à testemunha. Em outro estudo realizado por Zanandrea et al. (2004), os autores observaram que o óleo essencial de Origanum vulgare L. adicionado ao meio de cultivo reduziu significativamente o crescimento micelial de Alternaria sp., Bipolaris oryzae, Curvularia sp. e Rhizoctonia solani. O óleo essencial de candeia apresenta $\alpha$ bisabolol, como componente principal, que contém sesquiterpenos citotóxicos (lqbal et al., 2001) e é possível que este componente tenha sido um dos responsáveis pela inibição observada.

Em relação ao óleo essencial de alecrim foi observado $100 \%$ de inibição do crescimento micelial de $R$. solani em todas as concentrações testadas (Figura 2). Para Alternaria sp. o mesmo ocorreu nas alíquotas de 60, 200, 500 e $1000 \mu \mathrm{L}$, sendo que nas demais concentrações (100, 40 e $20 \mu \mathrm{L})$ a inibição foi diminuindo gradativamente. Para $A$. carthami, houve inibição total somente a partir de $100 \mu \mathrm{L}$.

Trabalhos realizados por Daferera et al. (2003) indicaram que in vitro o óleo essencial de alecrim não foi eficiente no controle de Botrytis cinerea, Fusarium solani var. coeruleum e Clavibacter michiganensis nas concentrações estudadas, pois somente a partir de 606 e $668 \mathrm{mg} \mathrm{mL}^{-1}$ foi que ocorreu redução de $50 \%$ do crescimento micelial de $B$. cinerea e Fusarium, respectivamente. Nozaki et al. (1999) estudando o efeito de alecrim, no crescimento micelial dos fungos Alternaria sp., $A$. carthami e Sclerotium rolfsii, verificaram que alíquotas acima de $60 \mu \mathrm{L}$ do óleo essencial promoveram inibição completa de S.rolfsii, enquanto que alíquotas acima de $200 \mu \mathrm{L}$ causaram inibição de $100 \%$ no crescimento de Alternaria sp., o que está de acordo com os obtidos neste trabalho. Itako et al. (2009) verificaram que o extrato bruto aquoso de $R$. officinalis apresentou efeitos significativos na inibição do crescimento micelial, esporulação e germinação de esporos de Cladosporium fulvum. Nas concentrações de $20 \%$ e $40 \%$ reduziu $85,72 \%$ e $93,49 \%$ a esporulação, respectivamente.

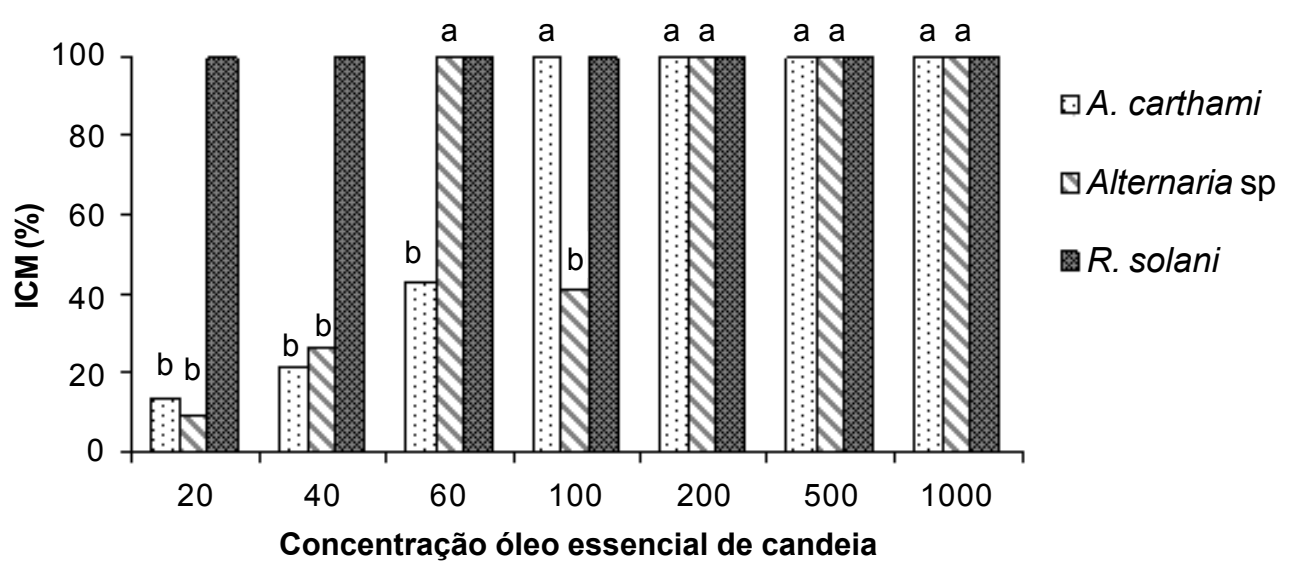

FIGURA 1. Efeito de diferentes concentrações do óleo essencial de candeia na inibição do crescimento micelial (ICM \%) in vitro de alguns fitopatógenos fúngicos. Médias seguidas pela mesma letra não diferem pelo teste de Scott-Knott a $5 \%$ de probabilidade. 


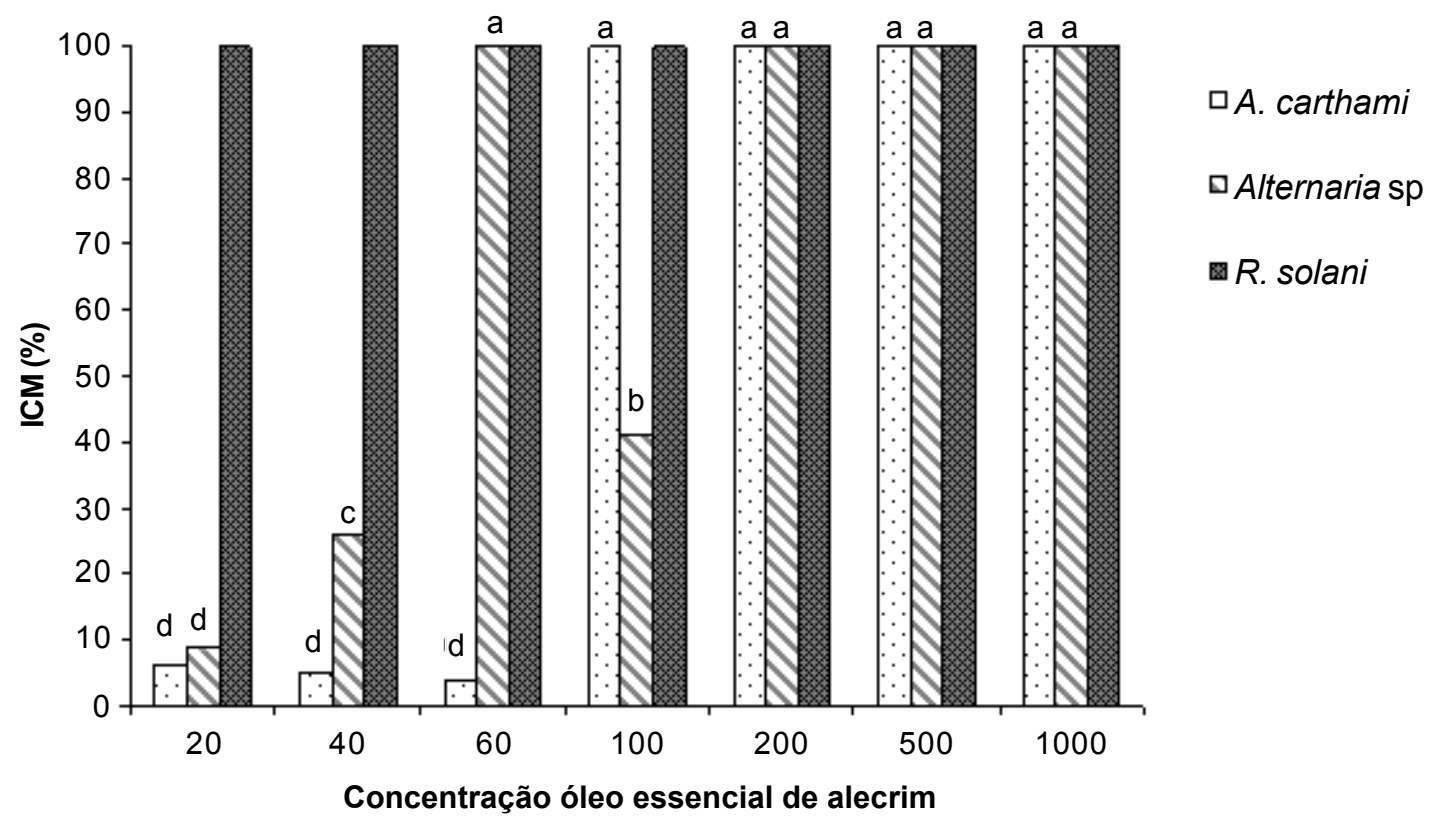

FIGURA 2. Efeito de diferentes concentrações do óleo essencial de alecrim na inibição do crescimento micelial (ICM \%) in vitro de alguns fitopatógenos fúngicos. Médias seguidas pela mesma letra não diferem pelo teste de Scott-Knott a $5 \%$ de probabilidade.

As melhores taxas de inibição do crescimento micelial dos patógenos foram observadas quando se adicionou o óleo essencial de palmarosa ao meio de cultura (Figura 3). Outros autores observaram resultados semelhantes quando trabalharam com C. martinii. Wilson et al. (1997) verificaram que os óleos essenciais de C. martinii e de C. citratus inibiram totalmente a germinação de esporos de Botrytis cinerea, até mesmo em baixas concentrações do óleo, como 0,39 e 6,25\%, respectivamente. Estas espécies medicinais também foram estudadas por Carvalho et al. (2008) no controle do fungo Colletotrichum gloeosporioides em frutos de pimentão. $O$ extrato bruto das duas espécies não inibiu o crescimento micelial, a esporulação e a germinação dos esporos, porém inibiu a formação de apressórios.

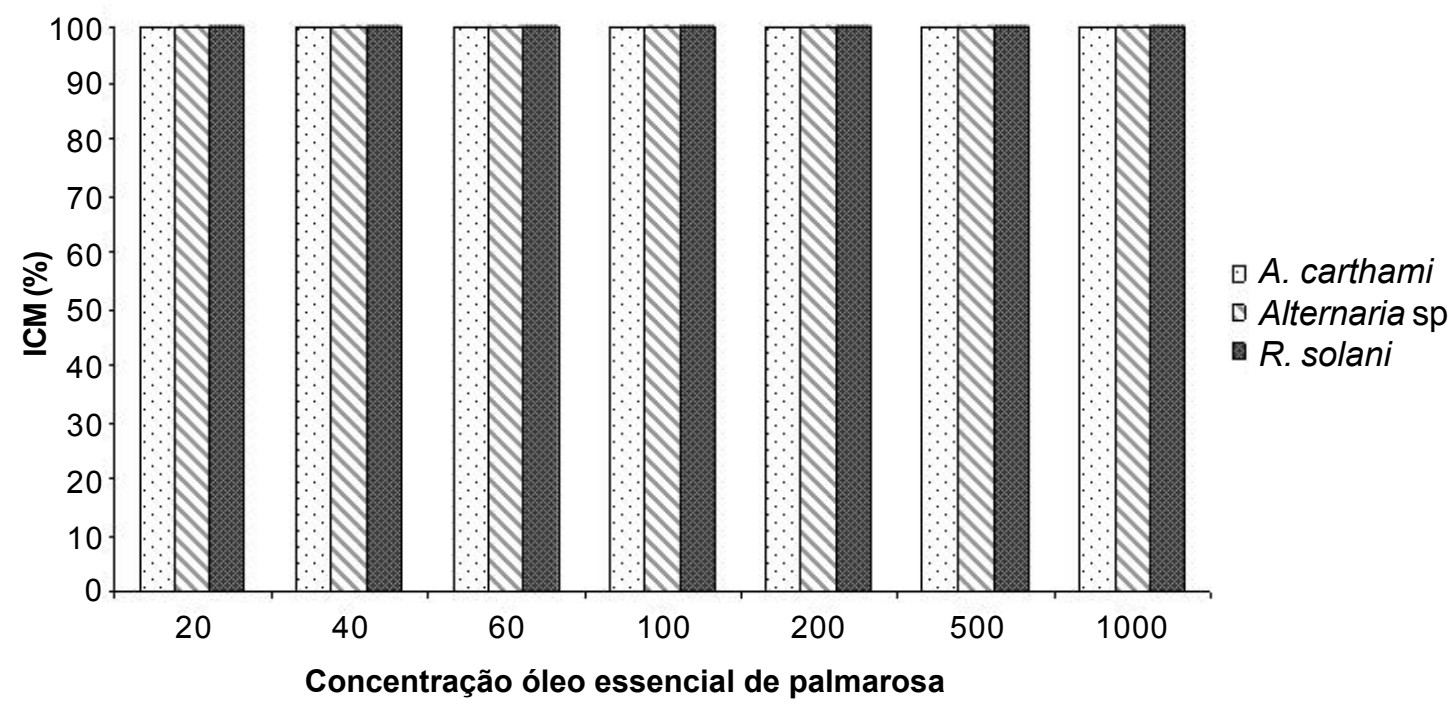

FIGURA 3. Efeito de diferentes concentrações do óleo essencial de palmarosa na inibição do crescimento micelial (ICM) in vitro de alguns fitopatógenos fúngicos. Médias seguidas pela mesma letra não diferem pelo teste de ScottKnott a $5 \%$ de probabilidade. 
Praschar et al. (2003) estudaram o efeito do óleo essencial de palmarosa sobre Saccharomyces cereviseae obtendo efeito antimicrobiano na concentração $0,1 \%$ do óleo. A composição deste óleo foi determinada com $65 \%$ de geraniol e $20 \%$ de geranil.

Outros estudos mostraram o efeito promissor dos óleos essenciais obtidos de diferentes plantas medicinais in vitro. Mello \& Amorim (2004), que testaram o óleo de Azadirachta indica contra o crescimento de Colletotrichum gloeosporioides, observaram que, independentemente da concentração do óleo, ocorreu inibição do crescimento micelial. Salgado et al. (2003) testaram a atividade fungitóxica de óleo de três espécies de eucalipto sobre Fusarium oxysporum, Botrytis cinerea e Bipolaris sorokiniana e obtiveram variadas taxas de inibição no crescimento micelial em todas as espécies para diferentes concentrações de óleo. Fiori et al. (2000) estudaram o efeito dos óleos essenciais de E.citriodora, Ageratum conyzoides e Cymbopogon citratus contra
Dydimella bryoniae e verificaram que os mesmos inibiram completamente o crescimento micelial e a germinação de conídios.

Tratamento de sementes por fumigação

Outro fator estudado neste trabalho foi a atividade do óleo essencial aplicado por fumigação na germinação e sanidade de sementes de soja, feijão e milho. Constatou-se, neste caso, a presença de fungos de armazenamento, tais como, Rhizopus $s p$, Aspergillus sp. e Penicillium sp. (Tabela 1).

No caso do feijão, as sementes assintomáticas germinadas e não germinadas e sementes sintomáticas germinadas tratadas com os óleos essenciais, não diferiram ou foram inferiores à testemunha (Tabela1). Pode-se inferir que as sementes germinaram independentemente do tratamento prévio. Para estas mesmas variáveis, observou-se que o óleo essencial de alecrim não apresentou uma combinação favorável entre

TABELA 1. Influência da aplicação por fumigação de óleos essenciais de candeia, alecrim e palmarosa na qualidade sanitária e fisiológica de sementes de feijão, soja e milho, expressos em porcentagem de germinação.

\begin{tabular}{|c|c|c|c|c|}
\hline Tratamento & $\begin{array}{l}\text { Sem. } \\
\text { assintomáticas } \\
\text { germinadas }\end{array}$ & $\begin{array}{l}\text { Sem. } \\
\text { assintomáticas } \\
\text { não germinadas }\end{array}$ & $\begin{array}{c}\text { Sem. } \\
\text { sintomáticas } \\
\text { germinadas }\end{array}$ & $\begin{array}{c}\text { Sem. } \\
\text { sintomáticas } \\
\text { não germinadas }\end{array}$ \\
\hline \multicolumn{5}{|c|}{ FEIJÃO } \\
\hline Testemunha & 87,75 b & $5,50 a$ & $4,75 b$ & $2,00 \mathrm{a}$ \\
\hline $\mathrm{NaOCl}$ & $86,31 \mathrm{~b}$ & $7,80 \mathrm{~b}$ & $4,25 \mathrm{~b}$ & $0,25 \mathrm{a}$ \\
\hline OE Candeia & $89,50 \mathrm{~b}$ & $4,40 \mathrm{a}$ & $4,50 \mathrm{~b}$ & $0,25 \mathrm{a}$ \\
\hline OE Alecrim & 56,25 a & $38,93 \mathrm{c}$ & 1,25 a & $3,50 \mathrm{a}$ \\
\hline OE Palmarosa & $87,81 \mathrm{~b}$ & $5,10 a$ & $4,75 b$ & $2,25 \mathrm{a}$ \\
\hline CV \% & 2,63 & 6,51 & 19,32 & 39,63 \\
\hline \multicolumn{5}{|c|}{ SOJA } \\
\hline Testemunha & $5,81 \mathrm{c}$ & $86,06 \mathrm{~d}$ & $3,30 \mathrm{~b}$ & $4,81 \mathrm{~b}$ \\
\hline $\mathrm{NaOCl}$ & $17,75 \mathrm{~d}$ & $70,56 \mathrm{c}$ & $1,75 \mathrm{a}$ & $9,81 \mathrm{c}$ \\
\hline OE Candeia & $3,25 b$ & $84,62 \mathrm{~d}$ & $0,50 \mathrm{a}$ & $11,31 d$ \\
\hline OE Alecrim & 57,93 e & $34,37 \mathrm{~b}$ & $3,25 b$ & $4,50 \mathrm{~b}$ \\
\hline OE Palmarosa & $0,00 \mathrm{a}$ & $0,00 \mathrm{a}$ & $97,37 \mathrm{c}$ & $2,62 \mathrm{a}$ \\
\hline CV \% & 6,39 & 1,79 & 3,44 & 11,75 \\
\hline \multicolumn{5}{|c|}{ MILHO } \\
\hline Testemunha & $65,50 \mathrm{~b}$ & $21,00 \mathrm{~b}$ & $11,68 \mathrm{c}$ & $1,80 \mathrm{~b}$ \\
\hline $\mathrm{NaOCl}$ & $68,06 \mathrm{c}$ & $22,50 \mathrm{c}$ & 7,87 b & $1,80 \mathrm{~b}$ \\
\hline OE Candeia & $74,37 \mathrm{~d}$ & $17,75 \mathrm{a}$ & $7,37 \mathrm{~b}$ & $0,50 \mathrm{a}$ \\
\hline OE Alecrim & $53,50 a$ & $45,37 \mathrm{~d}$ & 1,12 a & $0,00 \mathrm{a}$ \\
\hline OE Palmarosa & $77,87 \mathrm{e}$ & $21,62 \mathrm{~b}$ & $0,50 \mathrm{a}$ & $0,00 \mathrm{a}$ \\
\hline CV \% & 1,98 & 2,39 & 8,86 & 26,09 \\
\hline
\end{tabular}

Médias seguidas pela mesma letra nas colunas não diferem pelo teste de Scott-Knott a 5\% de probabilidade. * Média de 100 sementes por repetição. 
germinação e sanidade, apresentando-se menos eficiente do que os demais óleos e a testemunha em sementes assintomáticas ou quanto à porcentagem de incidência de patógenos. A concentração ou mesmo o tempo de exposição das sementes ao óleo essencial pode ter sido fitotóxica às sementes, interferindo nos mecanismos fisiológicos, e assim, impedindo a germinação.

As sementes de soja quando tratadas com óleo essencial de alecrim apresentaram $57 \%$ de germinação (Tabela 1). Já o óleo de palmarosa apresentou uma taxa de inibição de $100 \%$ da germinação das sementes. Este efeito pode estar relacionado com a alta concentração do óleo, ou a algum composto ou substância presente no mesmo capaz de impedir o processo de germinação, visto que entre os constituintes do óleo essencial de palmarosa temos a presença de compostos comprovadamente alelopáticos, como os terpenóides geraniol (70 a 90\%), limoneno, $\beta$-ocimeno, linalol, geranil acetato e $\beta$-cariofileno (Rao et al., 2001; Khanuja et al., 2005). O potencial herbicida dos óleos voláteis, inibindo a germinação de sementes e o crescimento de plântulas, pode ser atribuído a um dos componentes do óleo ou a ação conjunta dos componentes presentes no mesmo (AN et al., 1993). Em relação à ocorrência de patógenos, o mesmo apresentou alto índice de sementes doentes, correspondendo a $97 \%$ do total.

As sementes de milho assintomáticas germinadas (Tabela 1) e previamente tratadas com o óleo essencial de palmarosa apresentaram taxa de germinação $13 \%$ maior que a da testemunha. Em relação à ocorrência de patógenos, os óleos de alecrim e palmarosa mostraram maior efeito na proteção destas sementes, diferindo dos demais tratamentos.

Rodrigues et al. (2006) estudaram o óleo essencial da planta Ocimum gratissimum no tratamento de sementes contra Bipolaris sorokiniana em teste de areia e concluíram que o mesmo não teve influencia na emergência, altura e na massa fresca de plântulas, bem como na transmissão do patógeno, uma vez que tais parâmetros não se diferenciaram da testemunha. Já Cruz et al. (1999), quando utilizaram o blotter test, verificaram o efeito de hidrolados das plantas Ocimum, Artemisia, Rosmarinus e Zingiber em sementes de trigo tratadas por fumigação no controle de Helminthosporium sativum, Rhizopus, Aspergillus e Penicillium, e observaram redução no número de sementes infectadas e maior número de plântulas sadias e normais, com controle de $100 \%$ dos fitopatógenos em todos os tratamentos.

Lobato et al. (2007) estudaram o efeito do óleo essencial de Piper aduncum L. em diferentes concentrações no controle de Macrophomina phaseolina, o qual contribui para a deterioração das sementes de caupi. Os resultados mostraram redução na ocorrência de fitopatógenos de $84 \%$ para $16 \%$ devido ao tratamento na concentração de $0,5 \%$ do óleo essencial.

Dikshit et al. (1983) observaram a ação fungitóxica do óleo de Cedrus deodora no controle de Alternaria alternata, Aspergillus flavus, A. fumigatus, Cladosporium cladosporioides, Curvularia lunata e Paecilomyces variotti, em sementes de Coriandrum sativum. O óleo essencial mostrou-se mais efetivo do que os fungicidas sintéticos, não apresentando efeito adverso à germinação das sementes e crescimento das plântulas.

\section{CONCLUSÃO}

Os óleos essenciais de alecrim, candeia e palmarosa utilizados em diferentes alíquotas inibiram distintamente o crescimento micelial de Alternaria carthami, Alternaria sp. e Rhizoctonia solani. As maiores taxas de inibição do crescimento micelial de todos os patógenos (100\%) foram observadas quando se adicionou o óleo essencial de palmarosa ao meio de cultura a partir da concentração de $20 \mu \mathrm{L}$. O óleo essencial de candeia e de alecrim proporcionou $100 \%$ de inibição do crescimento micelial de todos os fitopatógenos a partir da concentração de $200 \mu \mathrm{L}$.

Os óleos essenciais de alecrim, candeia e palmarosa apresentaram efeito alelopático diferenciado sobre a germinação das sementes, ou seja, o óleo de alecrim proporcionou os menores percentuais de sementes assintomáticas germinadas de feijão (56,25\%) e de milho (53,50\%); enquanto que a menor percentagem de sementes assintomáticas germinadas de soja $(0,00 \%)$ foi obtida quando se utilizou o óleo essencial de palmarosa.

\section{REFERÊNCIA}

AN, M.et al. Mathematical modeling of allelopathy: biological response to allelochemicals and its interpretation. Journal of Chemical Ecology, v.19, n.10, p.2379-88, 1993.

CARVALHO, J.B. et al. Fungitoxicidade de Cymbopogon citratus e Cymbopogon martinii a Colletotrichum gloeosporioides em frutos de pimentão. Revista Brasileira de Plantas Medicinais, v.10, n.1, p.88-93, 2008.

COSTA, L.C.B. et al. Secagem e fragmentação da matéria seca no rendimento e composição do óleo essencial de capim-limão. Horticultura Brasileira, v.23, n.4, p.9569, 2005.

CRUZ, M.E.S. et al. Água aromatizada de plantas medicinais no tratamento de sementes de trigo. Fitopatologia Brasileira, v.24, supl., p.278, 1999.

DAFERERA, D.J.; ZIOGASB, B.N.; POLISSIOU, M.G. The effectiveness of plant essential oils on the growth of Botrytis cinerea, Fusarium sp. and Clavibacter 
michiganensis subsp. michiganensis. Crop Protection, v.22, n.1, p.39-44, 2003.

DIKSHIT, A. et al. Cedrus oil - a promising storage fungitoxicant. Journal of Stored Products, v.19, p.15962, 1983.

FERREIRA, D.F. SISVAR 4.6. Sistema de análises estatísticas. UFLA: Lavras, 2003.

FIORI, A.C.G. et al. Antifungal activity of leaf extracts and essential oils of some medicinal plants against Didymella bryoniae. Journal of Phytopathology, v.148, p.483-7, 2000.

IQBAL, M.C.M. et al. Antifungal activity from water extracts of some common weeds. Pakistan Journal of Biological Sciences, v.4, n.7, p.843-5, 2001.

ITAKO, A.T. et al. Controle de Cladosporium fulvum em tomateiro por extratos de plantas medicinais. Arquivos do Instituto Biológico, v.76, p.75-83, 2009.

KHANUJA, S.P.S. et al. Essential oil constituents and RAPD markers to establish species relationship in Cymbopogon Spreng. (Poaceae). Biochemical Systematics and Ecology, v.33, p.171-86, 2005.

LOBATO, A.K.S. et al. Ação do óleo essencial de Piper aduncum $\mathrm{L}$. utilizado como fungicida natural no tratamento de sementes de Vigna unguiculata (L.) Walp. Revista Brasileira de Biociências, v.5, p.915-7, 2007. MACHADO, J.C. Tratamento de sementes no controle de doenças. Lavras: LAPS/UFLA/FAEPE, 2000. 138p.

MATOS, F.J.A. As plantas da farmácia viva. Fortaleza: Universidade Federal do Ceara, 1997. 57p.

MÉDICE, R. et al. Óleos essenciais no controle da ferrugem asiática da soja Phakopsora pachyrhizi Syd. \& P. Syd. Ciência e Agrotecnologia, v.31, n.1, p.83-90, 2007.

MELLO, A.S.F.; AMORIM, L. Comportamento in vitro de Colletotrichum gloeosporioides na presença de óleo de nim. Fitopatologia Brasileira, v.29, supl., p.130-1, 2004. NOZAKI, M.H. et al. Rosmarinus officinalis no controle de fitopatógenos. Fitopatologia Brasileira, v.24, supl., p.311, 1999.

PEREIRA, R.B. et al. Extrato de casca de café, óleo essencial de tomilho e acibenzolar-S-metil no manejo da cercosporiose-do-cafeeiro. Pesquisa Agropecuária Brasileira, v.43, p.1287-96, 2008.

PRASHAR, A. et al. Antimicrobial action of palmarosa oil (Cymbopogon martinii) on Saccharomyces cerevisiae. Phytochemistry, v.63, n.5, p.569-75, 2003.

RAO, E.V.S.P. et al.. Studies on in situ soil moisture conservation and additions of phosphorus and potassium in rainfed palmarosa (Cymbopogon martini var. motia) in a semi-arid tropical region of India. European Journal of Agronomy, v.14, p.167-72, 2001. RODRIGUES, E.A. et al. Potencial da planta medicinal Ocimum gratissimum no controle de Bipolaris sorokiniana em sementes de trigo. Acta Scientiarum Agronomy, v.28, n.2, p.213-20, 2006.

SALGADO, A.P.S.P. et al. Aspectos da atividade fungitóxica dos óleos essenciais das folhas de Eucalyptus sobre os gêneros Fusarium oxysporum, Botrytis cinerea e Bipolaris sorokiniana. Ciência e Agrotecnologia, v.27, n.2, p.17-22, 2003.

SALUSTIANO, M.E. et al. Extratos de candeia (Eremanthus erythropappus (DC.) MacLeish) na inibição in vitro de Cylindrocladium scoparium e de quatro espécies de ferrugens. CERNE, v.12, p.189-93, 2006. SCHWAN-ESTRADA, K.R.F.; STANGARLIN, J.R. Extratos e óleos essenciais de plantas medicinais na indução de resistência. In: CAVALCANTI, L.S. et al. Indução de resistência em plantas a patógenos e insetos. Piracicaba: Fealq, 2005. p.125-32.

SILVA, D.M.H.; BASTOS, C.N. Atividade antifúngica de óleos essenciais de espécies de Piper sobre Crinipellis perniciosa, Phytophthora palmivora e Phytophthora capsici. Fitopatologia Brasileira, v.32, p.143-5, 2007. VENZON, M. el al. Controle alternativo de pragas e doenças. Viçosa: EPAMIG, UFV, 2006. 206p.

WILSON, C.L. et al. Rapid evaluation of plant extracts and essential oils for antifungal activity against Botrytis cinerea. Plant Disease, v.81, p.204-10, 1997.

ZANANDREA, L. et al. Atividade do óleo essencial de orégano contra fungos patogênicos do arroz: crescimento micelial de fungos em placas. Revista Brasileira de Farmacognosia, v.14, supl.1, p.14-6, 2004. 